\title{
A farm-level assessment of labor and mechanization in Eastern and Southern Africa
}

\author{
Frédéric Baudron ${ }^{1}$ (D) $\cdot$ Michael Misiko $^{2} \cdot$ Bisrat Getnet $^{3} \cdot$ Raymond Nazare $^{4} \cdot$ John Sariah $^{5} \cdot$ Pascal Kaumbutho $^{6}$
}

Accepted: 7 February 2019 / Published online: 4 March 2019

(C) INRA and Springer-Verlag France SAS, part of Springer Nature 2019

\begin{abstract}
Once again, agricultural mechanization is top on the policy, research, and development agendas in sub-Saharan Africa. However, whether labor is limiting in this region - and mechanization is in demand - remains debated. The hypothesis of this study is that labor is a major limiting factor to the productivity of most farming systems in Africa. We used farm-level data (including detailed labor data) from eight sites dominated by smallholder agriculture and spanning four countries in Eastern and Southern Africa, and analyzed this unique dataset using multivariate methods (generalized linear models, boundary line analysis, and binary classification and regression trees). Labor and/or other sources of farm power (draught power or tractor power) were found to limit land productivity in all study sites. We also found that the overall contribution of female labor to farming was much lower than commonly stated - between 7 and 35\% - and that the labor intensity experienced by women in agriculture was dependent to a large degree on men's tasks. Our results reveal a much higher demand for mechanization than previously found by macroeconomic analyses, and point to a problem of access rather than demand. Our results also add to recent evidence debunking the persistent myth that women provide the bulk of the farming labor, and demonstrate that reducing labor intensity experienced by women in farming depends to a large degree upon understanding labor intensity experienced by men, rather than poorly founded generalizations about how women are overworked. This is the first time farm-level data containing detailed labor assessment and spanning four countries are used to assess mechanization demand in Africa. This paper also plays a pioneering role in debunking a number of myths related to labor in African smallholder agriculture, with implications for the mechanization agenda of the region.
\end{abstract}

Keywords Agricultural intensification · Drudgery · Gender gap · Land consolidation

\section{Introduction}

After more than two decades of low interest and minimum investments in agricultural mechanization, the topic is back on the agenda of policy, research, and development in sub-Saharan Africa (SSA) (e.g., Daum and Birner
2017; FAO and AUC 2018). This renewed interest was indeed epitomized by the statement of the chairperson of the African Union Commission during the 2015 African Union Summit, when she declared "we must retire the handheld-hoe to the museum, and provide access to modern technology" (https://au.int/web/sites/default/files/
Frédéric Baudron

f.baudron@ cgiar.org

Michael Misiko

m.misiko@cgiar.org

Bisrat Getnet

bisrat.get@gmail.com

Raymond Nazare

rnazare2003@gmail.com

John Sariah

jsariah@yahoo.com
Pascal Kaumbutho

pascalgk@agrimechafrica.co.ke

1 CIMMYT (International Maize and Wheat Improvement Center), 12.5 km Peg Mazowe Road, Harare, Zimbabwe

2 CIMMYT, Nairobi, Kenya

3 Ethiopian Institute of Agricultural Research, Addis Ababa, Ethiopia

4 University of Zimbabwe, Harare, Zimbabwe

5 Selian Agricultural Research Institute, Arusha, Tanzania

6 Kenya Network for Dissemination of Agricultural Technologies, Nairobi, Kenya 
speeches/25429-sp-intergenerational_dialogue_speech 22 may final.pdf; Fig. 1).

However, whether there is enough demand for mechanization in SSA remains debated (Pingali 2007; Diao et al. 2016). On one hand, farming systems have intensified - with fallows having all but disappeared in many countries (BinswangerMkhize and Savastano 2017). The value added by agriculture (i.e., the net output of the sector after adding up all outputs and subtracting intermediate inputs) has also increased, particularly since the turn of the century (Baudron et al. 2015). On the other hand, land to labor ratios remain low in most of the region and are projected to decrease further, while cropping intensity and input use remain very low compared to other regions (Headey and Jayne 2014; Binswanger-Mkhize and Savastano 2017).

Assessments of demand for mechanization, however, are dominated by macroeconomic analyses, which use data that may be too aggregated to capture regional and householdlevel diversity in terms of mechanization use and demand (Sims and Kienzle 2006; Diao et al. 2016). In this study, we assess the demand for mechanization through an analysis centered on the farming household, by using a unique dataset that includes detailed labor data collected in eight sites spanning four countries in Eastern and Southern Africa (ESA). Our specific objectives were as follows:

1. To explore evidence that labor (and other sources of farm power) limits the productivity of smallholder farms in ESA

2. To identify the tasks for which mechanization should be prioritized

Considering the strong focus of many current mechanization interventions in SSA on women (including the African Union Commission), a secondary objective of this study was to assess the gender implications (in terms of gender gap and gender disaggregation of labor) of the current low levels of mechanization in ESA. This theme has been little explored; there is still more research focus and analyses on seed, fertilizer, climate change, labor, natural resource management, etc. (Doss 2001 Peterman et al. 2014), compared to analyzing gender issues in mechanization. Finally, with land consolidation being often presented as a prerequisite to mechanization (Asiama et al. 2017), another secondary objective of this study was to assess current relations between farm size and productivity.

\section{Materials and methods}

\subsection{Study sites}

The study was carried out in the eight sites where the project FACASI (Farm Power and Conservation Agriculture for Sustainable Intensification; www.facasi.act-africa.org) was implemented between 2013 and 2017: Assela and Hawassa in Ethiopia, Bungoma and Laikipia in Kenya, Arumeru and Mbulu in Tanzania, and Domboshawa and Makonde in Zimbabwe. These sites were selected as being (1) representative of maize-based and wheat-based smallholder farming systems in ESA and (2) clusters of implementation of other sustainable intensification projects led by the International Maize and Wheat Improvement Centre (CIMMYT), the Ethiopian Institute of Agricultural Research (EIAR), the Kenya Network for Dissemination of Agricultural Technologies (KENDAT), the Selian Agricultural Research Institute (SARI), and the University of Zimbabwe (UZ).

Assela is located in the Southern Highlands of Ethiopia at an average altitude of $2430 \mathrm{~m}$ above sea level and is characterized by a mean annual rainfall of $752 \mathrm{~mm}$ per year (32-year
Fig. 1 More than half of the land in Eastern and Southern Africa, more than two-thirds of the land in West Africa, and more than three-quarters of the land in Central Africa are prepared using the hand hoe (FAO and AUC 2018). During the 2015 African Union Summit, the chairperson of the African Union Commission declared "we must retire the handheld-hoe to the museum, and provide access to modern technology." Photo credit: Frédéric Baudron/CIMMYT

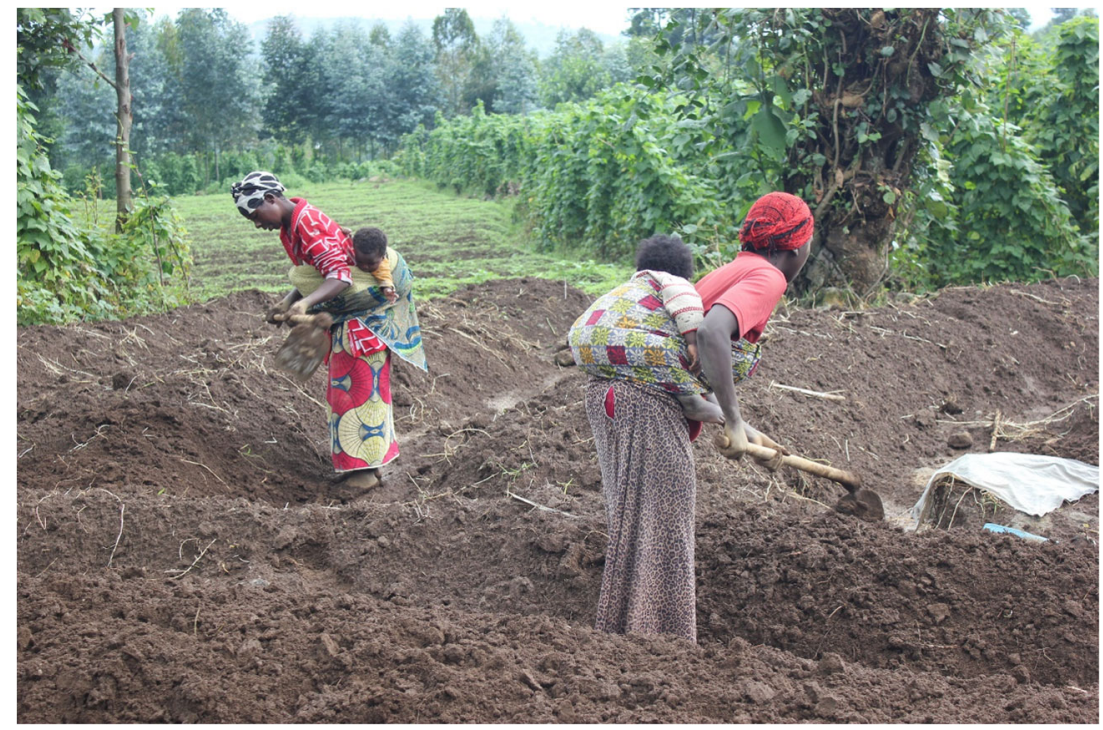


average) and a mean annual temperature of $17{ }^{\circ} \mathrm{C}$ (32-year average). Luvisols and vertisols are the major soil types. The main crops are teff, barley, wheat, and maize. The main livestock species are cattle, poultry, sheep, and goats. The population density is about 285 inhabitants $\mathrm{km}^{-2}$.

Hawassa is located in the Rift Valley of Ethiopia at an average altitude of $1708 \mathrm{~m}$ above sea level and is characterized by a mean annual rainfall of $968 \mathrm{~mm}$ per year (32-year average) and a mean annual temperature of $20{ }^{\circ} \mathrm{C}$ (32-year average). Fluvisols and luvisols are the major soil types. The main crops are maize, barley, teff, and sorghum. The main livestock species are cattle, sheep, goats, and poultry. The population density is about 6300 inhabitants $\mathrm{km}^{-2}$.

Bungoma is located in Western Kenya at an average altitude of $1614 \mathrm{~m}$ above sea level and is characterized by a mean annual rainfall of $1618 \mathrm{~mm}$ per year and a mean annual temperature of $21.5^{\circ} \mathrm{C}$. Acrisols and ferralsols are the major soil types. The main crops are maize, sugarcane, sunflower, potato, beans, and banana. The main livestock species are cattle, sheep, goats, and chicken. The population density is about 482 inhabitants $\mathrm{km}^{-2}$.

Laikipia is located in the Rift Valley of Kenya at an average altitude ranging from 1500 to $2600 \mathrm{~m}$ above sea level and is characterized by a mean annual rainfall ranging from 400 to $750 \mathrm{~mm}$ per year and a mean annual temperature ranging from 22 to $26^{\circ} \mathrm{C}$ in the low altitudes and from 6 to $14{ }^{\circ} \mathrm{C}$ in the high altitudes. Pellic vertisols are the major soil type. The main crops are wheat, maize, beans, potatoes, and vegetables. The main livestock species are cattle, sheep, goats, poultry, and camels. The population density is about 51 inhabitants $\mathrm{km}^{-2}$.

Arumeru is located in the northern part of Tanzania at an average altitude of $1043 \mathrm{~m}$ above sea level and is characterized by a mean annual rainfall of $800 \mathrm{~mm}$ per year (8-year average) and a mean annual temperature of $28{ }^{\circ} \mathrm{C}$ (8-year average). Clay, volcanic ash, and clay loam are the major soil types. The main crops are maize, pigeon pea, and beans, and a diversity of vegetables and fruits. The main livestock species are cattle, goats, and chicken. The population density is about 277 inhabitants $\mathrm{km}^{-2}$.

Mbulu is located in the northwest part of Tanzania at an average altitude of $1930 \mathrm{~m}$ above sea level and is characterized by a mean annual rainfall of $600 \mathrm{~mm}$ per year (10-year average) and a mean annual temperature of $22{ }^{\circ} \mathrm{C}(10$-year average). Sandy clay loam and clay soils are the major soil types. The main crops are maize, beans, pigeon pea, sunflower, and garlic. The main livestock species are cattle, goats, sheep, and chicken. The population density is about 120 inhabitants $\mathrm{km}^{-2}$.

Domboshawa is located in the northeast part of Zimbabwe at an average altitude of $1500 \mathrm{~m}$ above sea level and is characterized by a mean annual rainfall of $900 \mathrm{~mm}$ per year and a mean annual temperature of $21{ }^{\circ} \mathrm{C}$. Sandy loams and limited red clays are the major soil types. The main crops are maize, sugar beans, and groundnuts. The main livestock species are cattle, goats, and chickens. The population density is about 0.2 inhabitants $\mathrm{km}^{-2}$.

Makonde is located in Northern Zimbabwe at an average altitude of $1450 \mathrm{~m}$ above sea level and is characterized by a mean annual rainfall of $800 \mathrm{~mm}$ per year and a mean annual temperature of $23{ }^{\circ} \mathrm{C}$. Red clays and sandy loams are the major soil types. The main crops are maize, soya beans, tobacco, and groundnuts. The main livestock species are cattle, goats, and chickens. The population density is about 0.16 inhabitants $\mathrm{km}^{-2}$.

\subsection{Farm survey}

In each site, the heads of 100 farming households were interviewed in 2013, using a standardized semi-structured questionnaire that addressed household composition, crop and livestock management, and labor use. Input, output, and labor use for cropping were collected for the three main crops-in terms of area-of the farming household. Questionnaires were administered only when express consent was granted. Households were selected using a systematic sampling procedure in study villages based on representative transect routes across the village in which every fourth household, on alternate sides of the track, was sampled. In case one of the selected households was not available, the next one was selected. This is a type of probability sampling, in which a random starting point was chosen on all transect routes. The sampling interval of 4 was arrived at by dividing the population sizes by the various target sample sizes, and based on square kilometers where the population was spread.

\subsection{Focus group discussion}

Two parallel focus group discussions (FGDs, Neuman 2006) were organized in each site: one with male participants and the other with female participants. The main theme was the source and level of drudgery in farm chores and the perceptions of men and women on farm labor. The FGD involved bringing in small groups of informed men and women (typically 8 to 10 per session) at locations identified and agreed upon by the participants. The gender-segregated FGD sessions discussed how mechanization could be enhanced among male and female smallholder householders. Each session lasted an average of $2.5 \mathrm{~h}$. Discussions were moderated, led, and facilitated by an experienced anthropologist, who set the agenda and posed initial sets of questions. A holistic understanding of smallholder mechanization situation was described, based on participants' comments and experiences. To enhance validity, (i) controls on data were established through quantification of responses; (ii) many (eight) FGDs were conducted, each having two parallel sessions; and (iii) all FGD sessions were based on a fixed set of core questions, structured to yield specific quantitative and 
qualitative information in a short time. We present qualitative data mainly on definitions or ranking of tasks or drudgery and prioritization of mechanization.

\subsection{Calculations and statistical analysis}

\subsubsection{Calculations}

For each farm, land productivity was calculated by dividing the total quantity of grain, roots, and tubers harvested and corrected for dry matter content by the total farm area. A dry matter content of $90 \%$ was used for cereals and pulses, and of $20 \%$ for roots and tubers. Harvest quantities and field areas were provided by farmers during the farm survey. To compare livestock ownership between farms, the livestock numbers reported in the survey were converted into tropical livestock units (TLU), using a value of $250 \mathrm{~kg}$ live weight for one TLU. Following the method of Jahnke (1982), sheep and goats were assumed to be equivalent to $0.1 \mathrm{TLU}$, horses $0.8 \mathrm{TLU}$, mules $0.7 \mathrm{TLU}$, donkeys $0.5 \mathrm{TLU}$, pigs $0.2 \mathrm{TLU}$, and all types of cattle 0.7 TLU. The quantities of fertilizer applied were converted into quantities of nitrogen $(\mathrm{N})$ and quantities of phosphorus pentoxide $\left(\mathrm{P}_{2} \mathrm{O}_{5}\right)$ using specific fertilizer compositions. Manures and composts were summed as amendments. Total hired labor was calculated by summing hired male labor, hired female labor, and pooled labor. Total family labor was calculated by summing male labor, female labor, and child labor. The labor used for first tillage, second tillage, and third tillage was summed under the category land preparation. The labor used for sowing, thinning, and transplanting was summed under the category crop establishment. The labor used for manure application, compost application, basal fertilizer application, and topdressing of fertilizer was summed under the category fertilization. The labor used for the application of herbicides and pesticides was summed under the category crop protection. The labor used for the various weeding operations was summed under the category weeding. Finally, the labor used for transporting harvested products, shelling, threshing, winnowing, and milling was summed under the category postharvest.

\subsubsection{Descriptive statistics}

Quantitative data were tested for normal distribution using Shapiro-Wilk normality tests. When testing for differences between male-headed households and female-headed households, Kruskal-Wallis (non-parametric) tests were used for medians.

\subsubsection{Generalized linear models}

Generalized linear models (GLMs) were used to assess the source of variability in land productivity for each site independently. A normal distribution was used for the sites of Assela and Domboshawa, and a log-normal distribution for all the other six sites, after testing for distribution using the function "qqp" of the package "car" in R. Model 1 aimed at testing the effect of the different sources of farm power when controlling for agronomic and socioeconomic variables. Model 2 aimed at testing the effect of the amount of labor invested in different tasks when controlling for the amount of animal draught and tractor power used and agronomic variables. Models were constructed as follows:

$$
\begin{aligned}
\text { (Model 1) } Y_{\mathrm{ijklm}}= & a+\mathrm{FA}+\beta \mathrm{FH}_{\mathrm{i}}+\gamma \mathrm{MG}_{\mathrm{j}}+\delta \mathrm{DP}_{\mathrm{k}}+\varepsilon \mathrm{CT}_{1} \\
& +\delta \mathrm{LV}+\varepsilon \mathrm{EM}_{\mathrm{m}}+\zeta \mathrm{N}+\eta \mathrm{P}+\theta \mathrm{AM}+\mathrm{\imath FLB} \\
& +\kappa \mathrm{HLB}+\lambda \mathrm{FDP}+\mu \mathrm{HDP}+\gamma \mathrm{FTR}+\xi \mathrm{HTR}+\mathrm{R} \\
(\text { Model 2) } Y=a+ & \beta \mathrm{FA}+\gamma \mathrm{N}+\delta \mathrm{P}+\varepsilon \mathrm{AM}+\zeta \mathrm{LP}+\eta \mathrm{CE}+\theta \mathrm{FT} \\
& +\mathrm{\iota CP}+\kappa \mathrm{WD}+\lambda \mathrm{TDP}+\mu \mathrm{TTP}+\gamma \mathrm{LP} \times \mathrm{CE} \\
& +\xi \mathrm{LP} \times \mathrm{WD}+\mathrm{oLP} \times \mathrm{TDP}+\pi \mathrm{LP} \times \mathrm{TTP}+\mathrm{R}
\end{aligned}
$$

where, $Y_{\mathrm{ijklmn}}$ represents land productivity; FA is the total farm area; $\mathrm{FH}_{i}$ is the $i$ th gender of the head of the household (male/female); $\mathrm{MG}_{j}$ is the $j$ th migrant status of the head of the household (migrant/non-migrant); $\mathrm{DP}_{k}$ is the $k$ th status of the household in terms of having dependents outside the household (having dependents/not having dependents); $\mathrm{CT}_{l}$ is the $l$ th status of the household in terms of having relatives outside the household contributing to it (relative contributing/ no relative contributing); $\mathrm{LV}$ is the livestock number; $\mathrm{EM}_{k}$ is the $k$ th status of the household in terms of the formal employment of its head (formal employment/no formal employment); $N$ is the rate of nitrogen applied; $P$ is the rate of phosphorus pentoxide applied; AM is the rate of amendment (manure and compost) applied; FLB is the total family labor per farm area; HLB is the total hired labor per farm area; FDP is the total farm draught power per farm area; HDP is the total hired draught power per farm area; FTR is the total farm tractor power per farm area; HTR is the total hired tractor power per farm area; LP is the total labor per unit of farm area invested in land preparation; $\mathrm{CE}$ is the total labor per unit of farm area invested in crop establishment; FT is the total labor per unit of farm area invested in fertilization; CP is the total labor per unit of farm area invested in crop protection; WD is the total labor per unit of farm area invested in weeding; TDP is the total draught power per unit of farm area; TTP is the total tractor power per unit of farm area; $R$ is the residual; and where $\alpha, \beta, \gamma, \delta, \varepsilon, \zeta, \eta, \theta, \iota, \kappa, \lambda, \mu, \nu, \xi, o$, and $\pi$ represent fixed effects values. A probability of 0.1 was used to test the significance of each factor. In each model, factors that had a $t$ value less than 0.1 were removed.

\subsubsection{Boundary line analysis}

To better understand the influence of labor and farm area on land productivity, GLMs were complemented by boundary 
line analyses. Boundary lines test the relationship between the maximum values of a given variable and another independent variable. In our case, boundary lines were used to test how attainable land productivity (i.e., the maximum land productivity expected) changed as a function of total labor used and farm area. For that, linear regressions were fitted through the 90th quantile using the R package "quantreg," for each site separately, and using total labor and farm area separately (i.e., 16 separate analyses).

\subsubsection{Binary classification and regression trees}

To rank factors explaining the variability of land productivity by order of importance, GLMs were complemented by binary classification and regression trees. Land productivity was used as the target variable and all the categorical and continuous agronomic and socioeconomic variables included model 1 (above) were used as independent variables. These included all the variables in model 1 (above). The classification trees were constructed for each site separately using the R package "rpart."

\section{Results and discussion}

\subsection{General description of farming systems across the eight sites}

Land productivity and labor productivity were low across the eight sites, averaging $1179 \mathrm{~kg} \mathrm{ha}^{-1}$ and $11.41 \mathrm{~kg}$ person day ${ }^{-1}$, respectively. The lowest land productivity and labor productivity were recorded for Laikipia. Land productivity tended to be higher in Assela (mean of $2331.3 \mathrm{~kg} \mathrm{ha}^{-1}$ ) and in Domboshawa (mean of $1672.9 \mathrm{~kg} \mathrm{ha}^{-1}$ ) than in the other sites. Labor productivity tended to be higher in Domboshawa (mean of $22.45 \mathrm{~kg}$ person day ${ }^{-1}$ ), Assela (mean of $20.71 \mathrm{~kg}$ person $\mathrm{day}^{-1}$ ), and Makonde (mean of $18.49 \mathrm{~kg}$ person day ${ }^{-1}$ ) than in the other sites. Farms tended to be small - with a mean farm size of 1.67 ha across the entire dataset - and to own few livestock - with a mean of 4.17 TLU across the entire dataset. Farms were particularly small $(<1 \mathrm{ha})$ in Hawassa and Bungoma (with a mean farm size of 0.74 ha in both sites), Arumeru (mean farm size of $0.97 \mathrm{ha}$ ), and Domboshawa (mean farm size of 0.79 ha). The largest farms were observed in Makonde (with a mean farm size of $4.63 \mathrm{ha}$ ). The lowest livestock ownership was recorded in Bungoma (with a mean of 1.58 TLU per farm) and the highest in Assela (with a mean of 8.20 TLU per farm). The proportion of female-headed households was significant in all sites except Hawassa (3.2\%) and Bungoma (7.3\%). It was particularly high in Domboshawa (34.4\%). Farming was found to be highly labor intensive (with a mean of 212.4 person day $\mathrm{ha}^{-1}$ across the eight sites), particularly so in Bungoma (mean of 477.4 person day ha ${ }^{-1}$ ) and
Laikipia (mean of 398.8 person day $\mathrm{ha}^{-1}$ ). Indeed, Mazoyer and Roudart (2006) estimate the typical area cultivated per worker at 1 ha for systems based on manual cultivation, 3 ha for systems based on animal-drawn cultivation using the ard, and 10 ha for systems based on animal-drawn cultivation using the plow, translating to a maximum labor intensity of 365 person day $\mathrm{ha}^{-1}, 122$ person day $\mathrm{ha}^{-1}$, and 36 person day ha ${ }^{-1}$ (these calculations consider fields to be under cultivation throughout the year and workers to provide labor every day of the year, hence the qualificative of "maximum" labor intensity). The lowest labor intensity was found for Makonde (mean of 110.4 person day $\mathrm{ha}^{-1}$ ). The use of animal draught power was small across the eight sites (mean of 25.2 pair day $\mathrm{ha}^{-1}$ ), except in Assela (mean of 92.5 pair day $\mathrm{ha}^{-1}$ ). It was negligible in Laikipia (mean of 1.2 pair day $\mathrm{ha}^{-1}$ ). The use of a tractor was negligible across the eight sites (mean of 2.4 tractor day ha ${ }^{-1}$ ), except in Hawassa (mean of 13.3 tractor day ha ${ }^{-1}$ ).

\subsection{Five persistent myths related to labor in African smallholder agriculture}

\subsubsection{Myth no. 1: labor is abundant and cheap; thus, farm power does not limit agricultural productivity}

The outputs of model 1 revealed that one or more components of farm power had a significant effect on land productivity in all of the eight sites: hired tractor power in Assela; farm draught power in Hawassa; hired labor in Bungoma; hired labor and hired draught power in Laikipia; family labor, hired labor, and farm draught power in Arumeru; family labor in Domboshawa; and hired labor, hired draught power, and hired tractor power in Makonde (Table 1). Effects tended to be positive, except for three instances which may illustrate yield penalties due to delays following land preparation using farm draught power (Arumeru), hired draught power (Makonde), or hired tractor power (Assela).

In addition, the boundary line analysis of land productivity as a function of total labor revealed that the attainable land productivity tended to increase with increasing labor investment in six of the eight sites (Fig. 2). These included sites characterized by small $(<1 \mathrm{ha})$ farms (Bungoma, Arumeru, and Domboshawa), high labor intensity (Bungoma), and high labor productivity (Assela, Domboshawa, and Makonde).

Finally, the examination of classification trees that were produced for each site separately revealed the importance of labor or another source of farm power in explaining the variability of land productivity, although a soil fertility/crop nutrition parameter was paramount for most of the sites studied (Fig. 3). The most important factor was $\mathrm{N}$ applied in Assela and Bungoma; $\mathrm{P}_{2} \mathrm{O}_{5}$ applied in Hawassa, Laikipia, and Makonde; and amendments (manure and compost) applied in Mbulu and Domboshawa. For these seven sites, the right part of the tree 


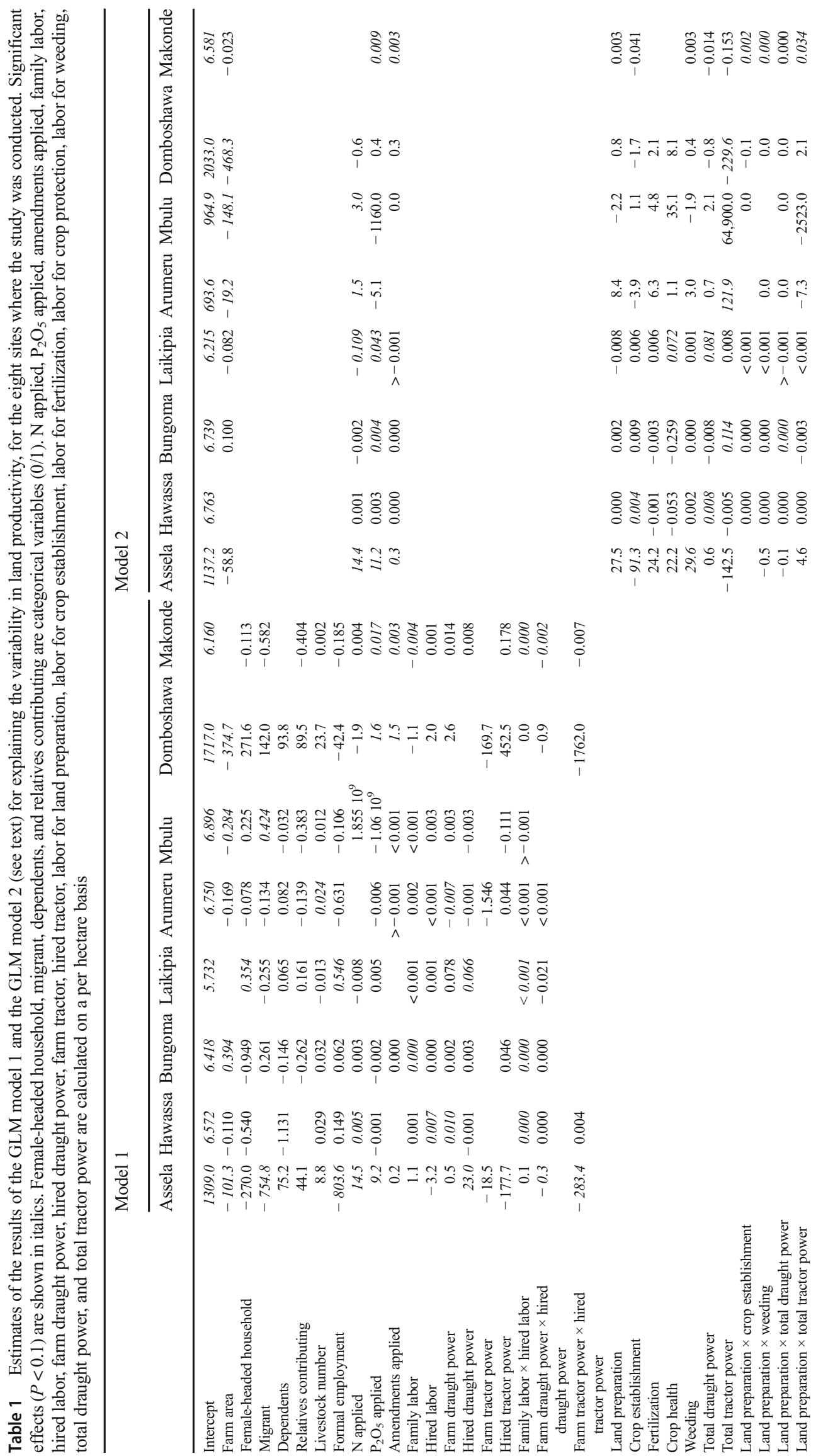



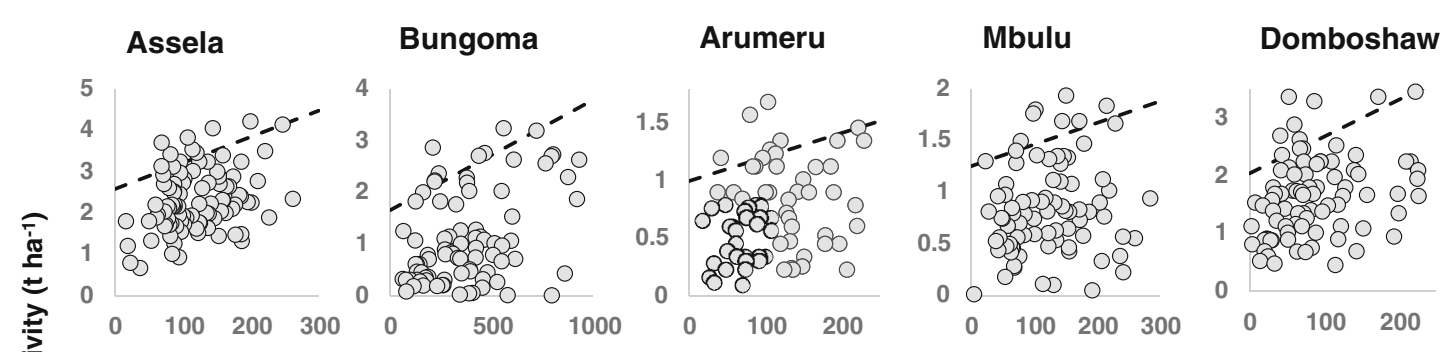

Makonde

Total labour (person.day ha-1)

\section{Assela}
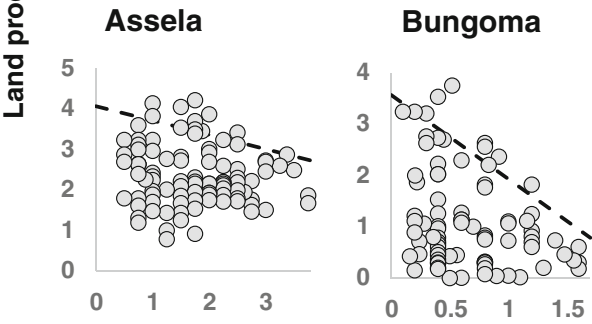

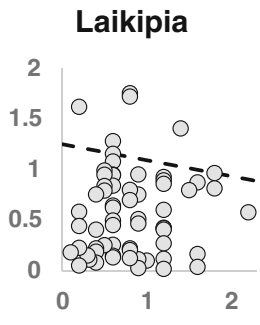

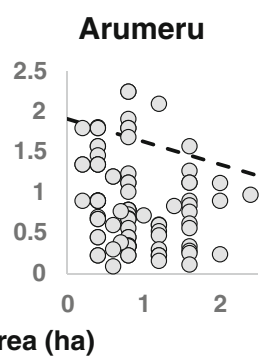

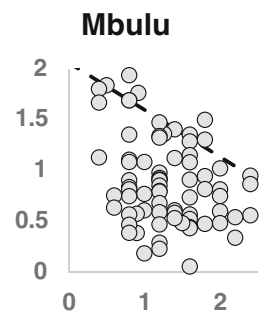

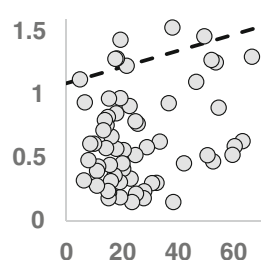

Makonde

2

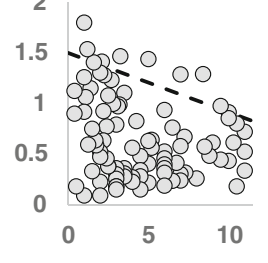

Fig. 2 Land productivity as a function of total labor (per unit of farm area), and as a function of farm area, for each site individually. Dashed lines represent linear regressions fitted through the 90th percentile. Only

(i.e., farm applying a higher rate of the input considered in the first node) was then split by a variable related to labor or another source of farm power: family labor in Bungoma and Mbulu, hired labor in Assela and Laikipia, farm draught power in Hawassa, and hired draught power in Arumeru. A variable related to labor or another source of farm power was also used to split the left part of three trees out of these seven trees: hired labor in Laikipia, farm draught power in Assela, and hired
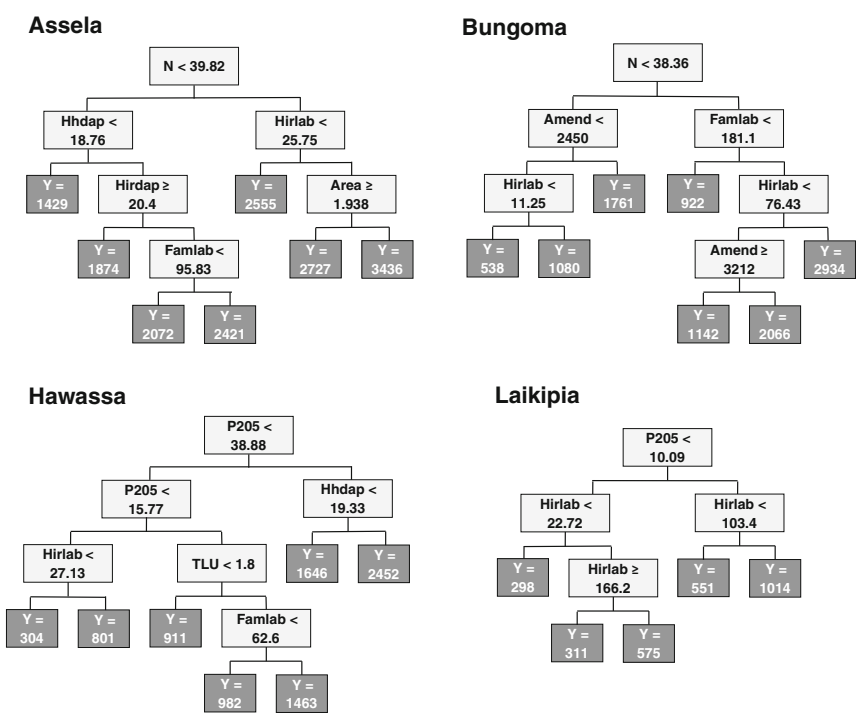

Fig. 3 Trees constructed by binary recursive partitioning rules using the R package "rpart" for land productivity, for each of the eight sites individually. For each node, the value used as threshold for the next split is given, as well as the average yield $(Y)$ for the terminal nodes. Mig, head of the household being migrant $(0=$ no, $1=$ yes $)$; TLU, total livestock number (tropical livestock units); Area, total farm area (ha); N, rate of nitrogen applied $\left(\mathrm{kg} \mathrm{ha}^{-1}\right) ; \mathrm{P}_{2} \mathrm{O}_{5}$, rate of phosphorus pentoxide sites with an increasing boundary line for land productivity as a function of total labor and sites with a decreasing boundary line for land productivity as a function of farm area are represented

tractor power in Makonde. For Arumeru, family labor was paramount, i.e., the criterion used in the first split. Hired labor was then the variable used to explain the variability in land productivity for farms characterized by relatively high family labor invested in farming $\left(\geq 52.12\right.$ person day ha $\left.{ }^{-1}\right)$.

Thus, the three analyses presented above are evidences that farm power is a major limiting factor to the productivity of smallholder agriculture in ESA and illustrate a much higher
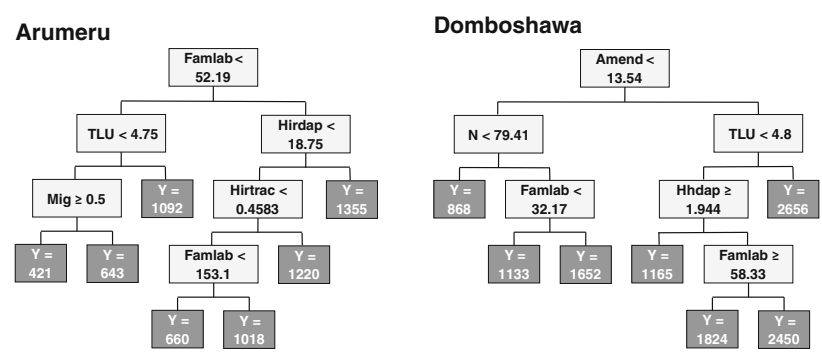

Mbulu
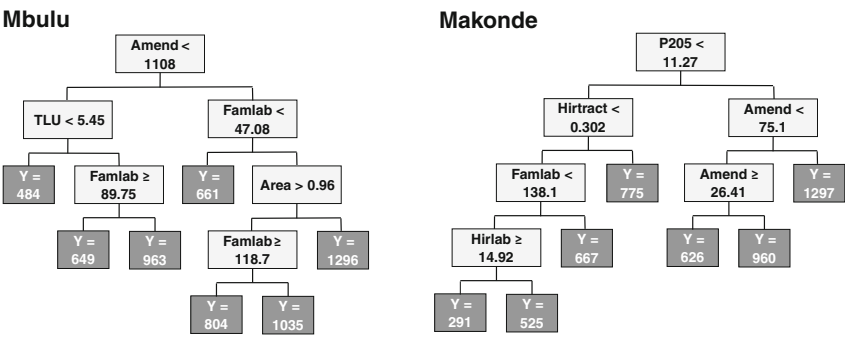

applied $\left(\mathrm{kg} \mathrm{ha}^{-1}\right)$; Amend, rate of manure and compost applied $\left(\mathrm{kg} \mathrm{ha}^{-1}\right)$; Famlab, total family labor used per unit of farm area (person day ha $\mathrm{ha}^{-1}$ ); Hirlab, total hired labor used per unit of farm area (person day ha ${ }^{-1}$ ); Hhdap, total household draught power used per unit of farm area (pair day ha ${ }^{-1}$ ); Hirdap, total hired draught power used per unit of farm area (pair day $\mathrm{ha}^{-1}$ ); Hirtrac, total hired tractor power used per unit of farm area (tractor day $\mathrm{ha}^{-1}$ ) 
demand for mechanization than revealed by macroeconomic analyses, pointing to a problem of access rather than demand. This calls for renewed efforts by governments in the region to create an enabling environment for the private sector to invest in the mechanization supply chains (Diao et al. 2016). Considering that markets are often weak, risky, and distorted in the region, this may also call for kick start subsidies (Benin et al. 2013). These subsidies, however, should be carefully designed to develop rather than distort the market for mechanization (Baudron et al. 2015; FAO and AUC 2018).
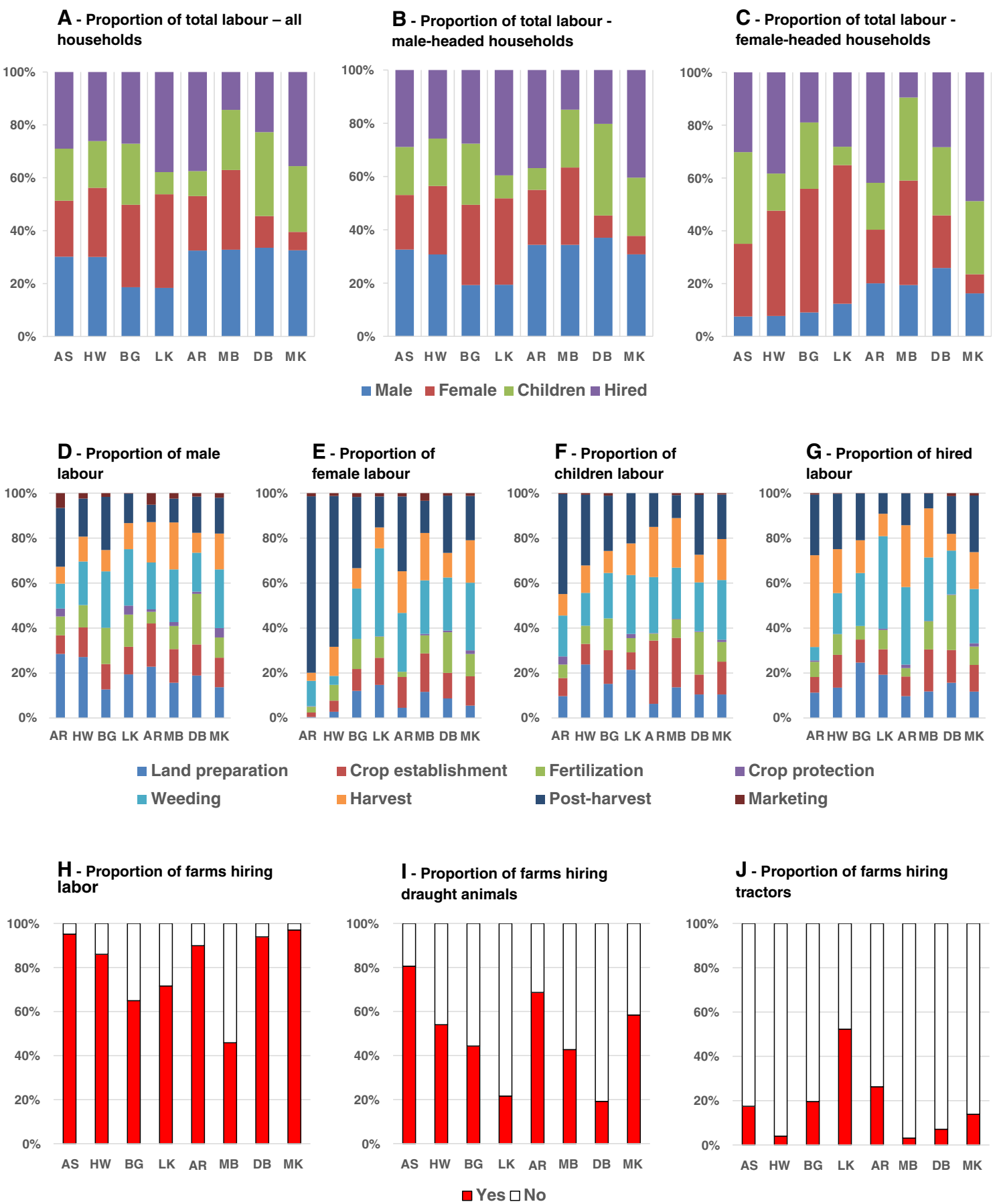

Fig. 4 Average labor disaggregation between male, female, child, and hired labor in a all households, $\mathbf{b}$ male-headed households only, and $\mathbf{c}$ femaleheaded households only, and for the eight sites where the study was conducted; average labor disaggregation between crop production tasks of $\mathbf{d}$ male, $\mathbf{e}$ female, $\mathbf{f}$ child, and $\mathbf{g}$ hired labor, for the eight sites where the study

was conducted; and percentage of households $\mathbf{h}$ hiring labor, $\mathbf{i}$ hiring draught animals, and $\mathbf{j}$ hiring tractors, for the eight sites where the study was conducted. AS Assela, Ethiopia; HW Hawassa, Ethiopia; BG Bungoma, Kenya; LK Laikipia, Kenya; AR Arumeru, Tanzania; MB Mbulu, Tanzania; DB Domboshawa, Zimbabwe; MK Makonde, Zimbabwe 


\subsubsection{Myth no. 2: most of the labor is provided by women}

Across the eight sites studied, women were found to provide 7 to $35 \%$ of the labor invested in farming (Fig. 4a), far less than the often-claimed percentage of 60 to $80 \%$ (Palacios-Lopez et al. 2017). Women tended to provide less labor to farming than men (except in Bungoma and Laikipia) and less than hired labor (except in Bungoma and Mbulu). Even when considering female-headed households alone, women were only the main providers of labor in half of the sites (Assela, Arumeru, Domboshawa, and Makonde; Fig. 4c): hired labor or children were in other sites. In two sites (Domboshawa and Makonde), male labor was higher than female labor in femaleheaded households. These results add to recent evidence debunking the persistent myth that women provide the bulk of the farming labor (Palacios-Lopez et al. 2017).

There were similarities in the definition of drudgery between all sites. Drudgery was defined based on the repetitive nature of the task, both physical and mental drain it caused, and the extent it had been mechanized or shared. In four sites, women and men ranked the same task as the most difficult: weeding in Bungoma, Laikipia, and Arumeru; and land preparation in Domboshawa. In Hawassa and Makonde, women dreaded land preparation the most, while men dreaded weeding the most. Similarly, men mentioned weeding as the most difficult task in Assela while women mentioned harvesting, and men mentioned land preparation as the most difficult task in Mbulu while women mentioned weeding. The largest share of female labor tended to be invested in activities characterized by high drudgery, weeding in particular (Fig. 4e). Still, this varied across sites. For instance, male invested a larger share of their labor in weeding in Assela and Hawassa than women (Fig. 4d, e). Weeding was also the main task performed by men in four of the sites (Bungoma, Laikipia, Mbulu, and Makonde; Fig. 4d). In fact, the results of our study reveal that weeding tended to be a shared task between men, women, children, and hired labor (Fig. 4d-g), and not as dominated by female labor as commonly thought. In addition, land preparation - which was classified as one of the dreariest task in three sites during the FGDs - represented a large share of male labor in all sites (Fig. 4d), challenging the common perception that tasks characterized by drudgery fall on women.

The largest share of female labor was invested in postharvest in five of the sites (Assela, Hawassa, Bungoma, Arumeru, and Makonde) and in weeding in three of the sites (Laikipia, Mbulu, and Makonde; Fig. 4e). Labor intensity of weeding is unlikely to be alleviated by mechanization, but instead by the adoption of herbicides. Whether farming households are likely to invest in herbicides is questionable, but the fact that their adoption would benefit the entire household and save resources to hire labor could imply that the demand for these inputs is high. There is also a large scope to mechanize postharvest operations — e.g., threshing, shelling, and milling — and alleviate women from this highly labor-intensive task. Indeed, demand tends to be high for such power-intensive operations and to take place even at low labor wage (Pingali 2007).

Even if this tended to be a male-dominated task, it is interesting to notice that women in all sites mentioned land preparation (and/or crop establishment) as a priority for mechanization during the FGDs, and not women-dominated tasks (such as weeding or postharvest operations). This apparent contradiction was clarified by FGD participants who explained that tasks were interlinked. A task was seen as a mechanization priority when it "opened the way" for other tasks. For instance, a timely and appropriate land preparation clears the way for early crop establishment and enables better (and cheaper) weed control. In all sites, tillage was often hastily done, which increased the cost of planting (labor), the brunt of weeding, and lateness in other field operations. Analyses showed mechanized land preparation would also reduce the need for women to travel frequently to serve men with food in the fields. This result presents a much more nuanced analysis of interrelations between male labor and female labor than usually presented in academic studies (Eerdewijk and Danielsen 2015). In summary, reducing drudgery among women also relied upon understanding men's chores and improving both as a two-way process rather than depending on poorly founded generalizations about how women are overworked.

\subsubsection{Myth no. 3: agricultural tasks are carried out almost entirely by family labor}

In all sites, the majority ( $>50 \%$ ) of farming households hired labor (Fig. 4h). The percentage of farming households hiring labor was especially high $(>85 \%)$ in Assela, Hawassa, Arumeru, Domboshawa, and Makonde. In addition, in half of the sites studied, the majority of farming households was hiring draught animals (Assela, Hawassa, Arumeru, and Makonde; Fig. 4i). Finally, the percentage of farming households hiring tractors was high in Laikipia ( $>50 \%)$, but small or negligible in other sites (Fig. 4j). This challenges the common view of Africa being dominated by family farms which, according to FAO, "rely mainly on the labor of family members" (Moyo 2016). African farming household may be far more dependent on labor markets than commonly assumed, and thus far more inclined to hire mechanization services. This argument was made previously by Baudron et al. (2015).

\subsubsection{Myth no. 4: consolidation, by enabling "efficient" mechanization, would have a positive impact on agricultural productivity}

Farm area was found to have a significant and negative effect on land productivity in three sites when using model 1 and in four sites when using model 2 (Table 1). Further, the boundary line analysis of land productivity as a function of farm area revealed 
that the maximum land productivity a farm can achieve decreased with increasing farm area in all sites except two (Fig. 2). This pattern was found for sites characterized by small-sized farms (Bungoma and Arumeru), medium-sized farms (Assela, Laikipia, and Mbulu), and large-sized farms (Makonde). This supports the negative farm size-productivity relationship which, although debated, has been reported elsewhere in ESA (e.g., Ali and Deininger 2015). If this relationship is as conspicuous in smallholder African agriculture as the present study suggests, this questions the potential impact of land consolidation on agricultural productivity in the region. As argued in Baudron et al. (2015), mechanization should not be a cause of consolidation, but should be driven by economic development instead. The concept of "appropriate mechanization" argues that machines should adapt to farm size, and not the opposite. Several countries in East and Southeast Asia underwent agricultural transformation while continuing to be dominated by small farms (Rigg et al. 2016). These countries tend to be highly mechanized (e.g., Bangladesh), but power is delivered by hundreds of thousands of small (single-axle) tractors and other small engines, not large (two-axle) tractors (Biggs et al. 2011). Such patterns of mechanization, however, are largely ignored by current interventions aiming at mechanizing agriculture in Africa, which tend to rely on (two-axle) tractors with a power range of 50 to $90 \mathrm{hp} \mathrm{(Cabral} \mathrm{2016).}$

Recent research and development initiatives taking place in the region point to the potential of using small single-axle tractors for agricultural mechanization in areas dominated by small and fragmented fields (Baudron et al. 2015; Kahan et al. 2017; http://knowledgeplatform.hellotractor.com). However, these initiatives remain at a pilot stage and whether singleaxle tractors will prove useful to mechanize smallholder farming outside of irrigated areas remains unproven (FAO and AUC 2018). Evidences of negative farm size-productivity relationship presented here call for further research to identify mechanization trajectories that do not require land consolidation where such relationship exists. Besides the negative social impact of land consolidation when the necessary structural transformation of the economy did not take place to absorb the labor force released from agriculture into the manufacturing sector, land consolidation may also generate negative environmental outcomes, e.g., by affecting biodiversity negatively through a loss of landscape heterogeneity.

\subsubsection{Myth no. 5: African agriculture is characterized by a wide gender gap}

We found limited evidence of consistent gender gap in the eight sites studied. Land productivity was found not to differ significantly between male-headed households and femaleheaded households in all eight sites except for Domboshawa and Makonde. If land productivity was found to be lower for female-headed households than for male-headed households in Makonde (with mean values of 643.9 and $474.2 \mathrm{~kg} \mathrm{ha}^{-1}$ for male-headed households and female-headed households, respectively), the opposite trend was found in Domboshawa (with mean values of 1554.7 and $1897.7 \mathrm{~kg} \mathrm{ha}^{-1}$ for maleheaded households and female-headed households, respectively). In addition, labor productivity and farm area did not differ significantly between male-headed households and female-headed households in all the eight sites. Finally, differences in livestock ownership between male-headed households and female-headed households were only significant in Mbulu (mean values of 6.45 and 3.60, respectively) but not in any of the seven other sites.

The fact that no evidence of gender gap was found in this study may stem from (1) the fact that resources are hugely inadequate in all these sites, limiting the possibility of large inequalities to clearly manifest; and (2) the fact that social capital may be high in these farming communities (more than often acknowledged in gender studies) as found during the FGDs. Social capital is a fundamental lifeline among female-headed households, who benefited from the help of male-headed households. This demands a harder look beyond gender-disaggregated productivity and to focus on communal livelihood relations (Peterman et al. 2014). This is not to deny the usefulness of current interventions targeting women-headed households, but rather to highlight the importance of preserving, strengthening, and tapping social mechanisms in rural communities. These constitute safety nets for women-headed households (and other vulnerable households). Further research to fully understand these mechanisms should be a priority on the policy agenda on gender. Of course, this study does not provide a full livelihood analysis. It did not compare income, food security, nutrition, access to information, etc., between male-headed households and female-headed households. It however suggests that women-headed households are as likely as their male-headed counterparts to benefit from mechanization, if mechanisms of equitable access are developed and applied.

\subsection{Implications for mechanization of smallholder agriculture in ESA}

This study provides strong empirical evidence that labor (and other sources of farm power) limits the productivity of many smallholder farming systems in ESA. In addition, the clear majority of smallholders was found to hire labor, draught power, and (to a lesser extent) tractor power (Fig. $4 \mathrm{~h}-\mathrm{j}$ ). Therefore, it is likely that smallholders would hire mechanization services, if they were accessible. Accessibility may be increased through interventions targeting financial inclusion (Women's World Bank 2016). This justifies the re-emergence of agricultural mechanization as a priority in the region.

However, many interventions currently underway in the region are based on (relatively) large tractors (Cabral 2016) which would require land consolidation to be used efficiently 
in many parts of sub-Saharan Africa (Asiama et al. 2017). Evidences of so-called inverse farm size-productivity relationship found in this study suggest that "appropriate mechanization," based on the use of small machines (Baudron et al. 2015), should also be considered for smallholder farms in ESA. However, our study focused on areas dominated by small farms. Our conclusions cannot therefore be generalized, as part of the region is witnessing a rise of medium-scale farms (Jayne et al. 2016) where (relatively) large forms of mechanization are no doubt more appropriate than the use of small machines. Identifying the niches where different pathways to mechanization are appropriate is urgent to inform policy makers. Ultimately, diverse patterns of mechanization will take place in most countries of the region, based on both the diversity of demand and the diversity of supply. Of course, one should not ignore the political dimension of the current mechanization interventions in the region, regardless of its appropriateness for the countries considered (Cabral 2016).

The outputs of model 2 revealed that labor for crop establishment, total draught power, total tractor power, and/or the interaction between labor for land preparation and labor for crop establishment had a significant effect on land productivity in all sites except Mbulu (Table 1). These effects tended to be positive (except for the effect of labor for crop establishment in Assela and total tractor power in Domboshawa), suggesting that priority for mechanization should be given to land preparation and crop establishment. FGD findings illustrate these are key to neutralizing male and female drudgery. These tasks are the most power intensive (Lal 2004; Pingali 2007). They are the most critical for crop productivity, as they are time bound. Delays in their completion often result in strong yield penalties, particularly where water is limiting (Thierfelder et al. 2018). Although previous studies have found that "the benefits that can be derived from the use of tractors are gendered" (Eerdewijk and Danielsen 2015), it was stated consistently (in all sites) by women during the FGDs conducted in this research that mechanizing land preparation and crop establishment would benefit both men and women as these tasks affect weeding intensity, one of the main tasks carried out by women and one that is associated with high drudgery. Such interrelations between male labor and female labor have rarely been acknowledged previously.

When looking at mechanizing land preparation and crop establishment, one should also look at the form this mechanization would take. Several mechanization options are available nowadays for mechanized direct seeding, also known as minimum tillage, or conservation agriculture when other components are incorporated, namely soil cover and crop diversification (Johansen et al. 2012). Although this depends on sitespecific soil properties (e.g., texture, soil moisture), direct seeding cuts energy requirements by about half compared to conventional plowing (Lal 2004). Thus, direct seeding (by reducing energy demand) may act synergistically with mechanization (which increases energy supply), resulting in mechanized direct seeding being one of the fastest and most energy-efficient option to establish a crop. The reduced energy requirements of direct seeding could also make the use of small tractor (see section on "appropriate mechanization" above), a viable option in rainfed conditions, as small tractors are often not powerful enough to plow conventionally but are well suited for direct seeding (Baudron et al. 2015). We recognize the low adoption of direct seeding in the region; however, the technology appears to have a large niche in ESA and its adoption rate is likely to increase when promoted in parallel with complementary practices, including mechanization (Johansen et al. 2012; Thierfelder et al. 2018). Furthermore, considering the impact conventional plowing may have on land degradation (Montgomery 2007), it is essential for mechanization interventions to consider minimum soil disturbance technologies.

Labor displacement (e.g., Beuchelt and Badstue 2013) is unlikely to occur with the mechanization of land preparation and crop establishment. Indeed, the largest share of hired labor was invested in weeding in five of the sites (Bungoma, Laikipia, Arumeru, Mbulu, and Makonde), and in postharvest in two of the sites (Hawassa and Makonde), not in land preparation and crop establishment (Fig. 4g). Therefore, weeding and postharvest operations could continue to be performed by hired labor even if land preparation and crop establishment are mechanized. Too often, mechanization is viewed as a complete shift from one source of power to another, for all operations, as encapsulated in the "ladder of mechanization." This conceptualization is wrong in our view. A source of power is rarely completely displaced by another. Usually, manual labor, draught power, and tractor power tend to coexist (as seen in all sites in this study). Priority should be given to mechanize the tasks that are the most power intensive and that are critical for productivity gains, while recognizing that other operations will continue to be performed by manual labor and draft power.

Looking at drudgery, and not merely at productivity, reducing the labor intensity of weeding and postharvest operations should also be a priority, as these tasks were mentioned as being some of the most tedious during the FGD sessions. Weeding intensity could be reduced by ensuring timely land preparation and crop establishment, as suggested by the results of the FGDs in this study. Postharvest mechanization technologies are likely to be in high demand, and observations by the authors suggest that they are spreading across ESA (although detailed research is needed to document this pattern and support it). Although not presented in this study (as not directly linked to farm productivity), women (as well as children in some of the sites) tended to spend tremendous time in transporting water and firewood. Providing transport solutions that reduce the drudgery-disproportionately placed on women (and children) - of transport by head-loading should be a focus of rural mechanization efforts. Moreover, with intensification, crop volumes to be harvested, transported and processed will increase, increasing the need for mechanization 
of these operations. It is thus important to not equate mechanization with "tractorization" (as is often the case) and to critically assess the demand for mechanization, including outside the boundary of the farm (i.e., rural mechanization).

\section{Conclusions}

Evidences presented in this study justify the current efforts to mechanize agriculture in Africa, as labor and other sources of farm power appear to be major limiting factors to the productivity of farming systems in the region. More than demand, which appears higher than found by previous macroeconomic studies, access may be what limits the expansion of mechanization the most in ESA. Governments in the region must therefore create an enabling environment for mechanization supply chains to develop. This includes the creation of mechanization (policy) instruments that further support smallholder demand. Parts of these instruments may be short-term smart subsidies that lay the ground for more sustainable practices. Sustainability requires that mechanization pathways promoted through policies are thought of carefully, devoid of false steps that are "copy-paste" tractorization programs promoted in the 1960s and 1970s on the continent (Pingali 2007). The "Sustainable Agricultural Mechanization for Africa" framework - released in 2018 - offers clear guides on sustainability and transformation of agricultural mechanization in Africa (FAO and AUC 2018). A majority of countries included in this study have recent policy instruments that address well the multiple dimensions of sustainable mechanization (the 2014 "Ethiopia National Agricultural Mechanization Strategy," the 2016 "National Agricultural Mechanization Policy" in Kenya, and the 2006 "Tanzania Agricultural Mechanization Strategy"; only in Zimbabwe is the main mechanization policy instrument - the National Policy on Agricultural Mechanization and Irrigation — still in draft form). However, many other policies (including energy policies, livestock policies, labor policies) have an impact on mechanization patterns and it is thus important to consider agricultural mechanization in the context of an overall agricultural growth strategy, as highlighted by Pingali (2007). One specific aspect of agricultural mechanization sustainability that requires further exploration is the change in greenhouse gas emissions following a shift from farming systems largely based on manual labor and draught power, to farming systems that are more dependent on fossil fuel energy.

Funding This study was funded by the Australian Centre for International Agricultural Research (ACIAR) (grant number FSC/2012/ 047) with additional support from CRP MAIZE and CRP WHEAT.

\section{Compliance with ethical standards}

Conflict of interest The authors declare that they have no conflict of interest.
Publisher's note Springer Nature remains neutral with regard to jurisdictional claims in published maps and institutional affiliations.

\section{References}

Ali DA, Deininger K (2015) Is there a farm size-productivity relationship in African agriculture? Evidence from Rwanda. Land Econ 91:317343. https://doi.org/10.3368/le.91.2.317

Asiama KO, Bennett R, Zevenbergen J (2017) Land consolidation for sub-Saharan Africa's customary lands - the need for responsible approaches. Am J Rural Dev 5:39-45. https://doi.org/10.12691/ AJRD-5-2-2

Baudron F, Sims B, Justice SE, Kahan DG, Rose R, Mkomwa S, Kaumbutho P, Sariah J, Nazare R, Moges G, Gérard B (2015) Reexamining appropriate mechanization in Eastern and Southern Africa: two-wheel tractors, conservation agriculture, and private sector involvement. Food Secur 7:889-904. https://doi.org/10.1007/ s12571-015-0476-3

Benin S, Johnson M, Abokyi E et al (2013) Revisiting agricultural input and farm support subsidies in Africa: the case of Ghana's mechanization, fertilizer, block farms, and marketing programs. IFPRI Discuss Pap 01300:1-121. https://doi.org/10.13140/RG.2.2.23891. 17447

Beuchelt TD, Badstue L (2013) Gender, nutrition- and climate-smart food production: opportunities and trade-offs. Food Secur 5:709-721. https://doi.org/10.1007/s12571-013-0290-8

Biggs S, Justice SE, Lewis D (2011) Patterns of rural mechanisation, energy and employment in South Asia: reopening the debate. Econ Polit Wkly xlvi:78-82

Binswanger-Mkhize HP, Savastano S (2017) Agricultural intensification: the status in six African countries. Food Policy 67:26-40. https:// doi.org/10.1016/j.foodpol.2016.09.021

Cabral L (2016) Brazil's tropical solutions for Africa: tractors, matracas and the politics of "appropriate technology". Eur J Dev Res 28:414 430. https://doi.org/10.1057/ejdr.2016.13

Daum T, Birner R (2017) The neglected governance challenges of agricultural mechanisation in Africa - insights from Ghana. Food Secur 9:959-979. https://doi.org/10.1007/s12571-017-0716-9

Diao X, Silver J, Takeshima H (2016) Agricultural mechanization and agricultural transformation. Washington D.C.

Doss CR (2001) Designing agricultural technology for African women farmers: lessons from 25 years of experience. World Dev 29:20752092. https://doi.org/10.1016/S0305-750X(01)00088-2

Eerdewijk A Van, Danielsen K (2015) Gender matters in farm power. Amsterdam, The Netherlands

FAO, AUC (2018) Sustainable agricultural development: a framework for Africa. Addis Ababa, Ethiopia

Headey DD, Jayne TS (2014) Adaptation to land constraints: is Africa different? Food Policy 48:18-33. https://doi.org/10.1016/j.foodpol. 2014.05.005

Jahnke HE (1982) Livestock production systems and livestock development in tropical Africa, Kieler Wis

Jayne TS, Chamberlin J, Traub L, Sitko N, Muyanga M, Yeboah FK, Anseeuw W, Chapoto A, Wineman A, Nkonde C, Kachule R (2016) Africa's changing farm size distribution patterns: the rise of medium-scale farms. Agric Econ (United Kingdom) 47:197-214. https://doi.org/10.1111/agec. 12308

Johansen C, Haque ME, Bell RW, Thierfelder C, Esdaile RJ (2012) Conservation agriculture for small holder rainfed farming: opportunities and constraints of new mechanized seeding systems. F Crop Res 132:18-32. https://doi.org/10.1016/j.fcr.2011.11.026

Kahan D, Bymolt R, Zaal F (2017) Thinking outside the plot: insights on small-scale mechanisation from case studies in East Africa. J Dev Stud 00:1-16. https://doi.org/10.1080/00220388.2017.1329525 
Lal R (2004) Carbon emission from farm operations. Environ Int 30:981990

Mazoyer M, Roudart L (2006) A history of world agriculture from the neolithic age to the current crisis, Earthscan. London, U.K.

Montgomery DR (2007) Soil erosion and agricultural sustainability. Proc Natl Acad Sci U S A 104:13268-13272. https://doi.org/10.1073/ pnas.0611508104

Moyo S (2016) Family farming in sub-Saharan Africa: its contribution to agriculture, food security and rural development. Brasília, Brazil

Neuman WL (2006) Social research methods: qualitative and quantitative approaches, 6th ed. Allyn \& Bacon, Boston, USA

Palacios-Lopez A, Christiaensen L, Kilic T (2017) How much of the labor in African agriculture is provided by women? Food Policy 67:52-63. https://doi.org/10.1016/j.foodpol.2016.09.017

Peterman A, Behrman JA, Quisumbing AR (2014) A review of empirical evidence on gender differences in nonland agricultural inputs, technology, and services in developing countries. In: Gender in Agriculture. Springer Netherlands, Dordrecht, pp 145-186
Pingali P (2007) Agricultural mechanization: adoption patterns and economic impact. In: Evenson R, Pingali P (eds) Handbook of agricultural economics, Elsevier. Amsterdam, The Netherlands, pp 2779 2805

Rigg J, Salamanca A, Thompson EC (2016) The puzzle of East and Southeast Asia's persistent smallholder. J Rural Stud 43:118-133. https://doi.org/10.1016/j.jrurstud.2015.11.003

Sims B, Kienzle J (2006) Farm power and mechnization for small farms in sub-Saharan Africa. FAO, Rome, Italy

Thierfelder C, Baudron F, Setimela P, Nyagumbo I, Mupangwa W, Mhlanga B, Lee N, Gérard B (2018) Complementary practices supporting conservation agriculture in southern Africa. A review. Agron Sustain Dev 38. https://doi.org/10.1007/s13593-018-0492-8

Women's World Bank (2016) Policy frameworks to support women's financial inclusion. New York, USA 